\title{
Additive Manufacturing of Molds for Fabrication of Insulated Concrete Block
}
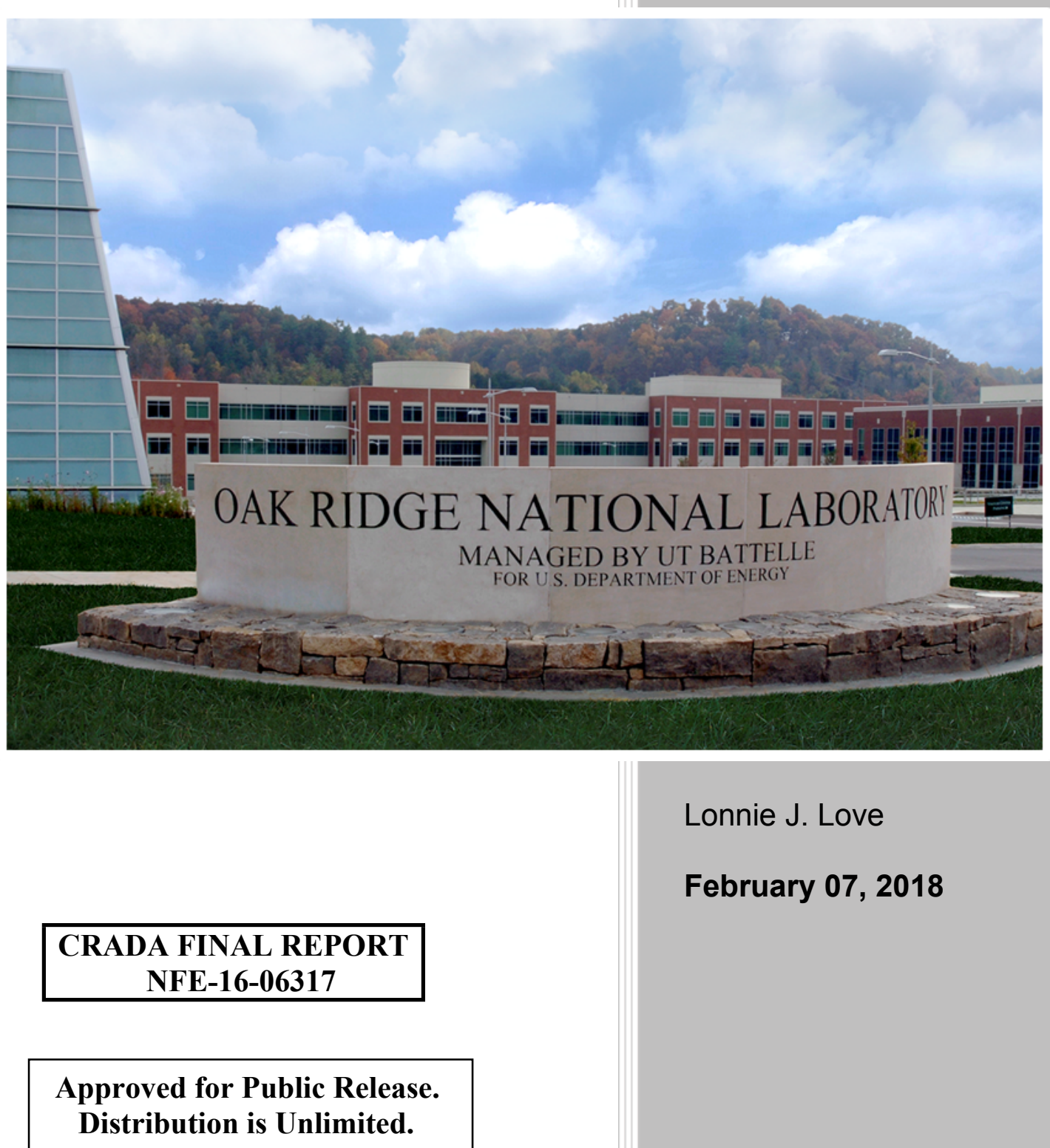

Lonnie J. Love

February 07, 2018 


\section{DOCUMENT AVAILABILITY}

Reports produced after January 1, 1996, are generally available free via US Department of Energy (DOE) SciTech Connect.

Website http://www.osti.gov/scitech/

Reports produced before January 1, 1996, may be purchased by members of the public from the following source:

National Technical Information Service
5285 Port Royal Road
Springfield, VA 22161
Telephone 703-605-6000 (1-800-553-6847)
TDD 703-487-4639
Fax 703-605-6900
E-mail info@ntis.gov
Website http://www.ntis.gov/help/ordermethods.aspx

Reports are available to DOE employees, DOE contractors, Energy Technology Data Exchange representatives, and International Nuclear Information System representatives from the following source:

Office of Scientific and Technical Information

PO Box 62

Oak Ridge, TN 37831

Telephone 865-576-8401

Fax 865-576-5728

E-mail reports@osti.gov

Website http://www.osti.gov/contact.html

This report was prepared as an account of work sponsored by an agency of the United States Government. Neither the United States Government nor any agency thereof, nor any of their employees, makes any warranty, express or implied, or assumes any legal liability or responsibility for the accuracy, completeness, or usefulness of any information, apparatus, product, or process disclosed, or represents that its use would not infringe privately owned rights. Reference herein to any specific commercial product, process, or service by trade name, trademark, manufacturer, or otherwise, does not necessarily constitute or imply its endorsement, recommendation, or favoring by the United States Government or any agency thereof. The views and opinions of authors expressed herein do not necessarily state or reflect those of the United States Government or any agency thereof. 
ORNL/TM-2018/775

CRADA/NFE- 16-06317

Energy \& Transportation Science Division

Advanced Manufacturing Office

Additive Manufacturing of Molds for Fabrication of Insulated Concrete Block

Authors

Lonnie J. Love

Peter D. Lloyd

Date Published:

February 07, 2018

\author{
Prepared by \\ OAK RIDGE NATIONAL LABORATORY \\ Oak Ridge, Tennessee 37831-6283 \\ managed by \\ UT-BATTELLE, LLC \\ for the \\ US DEPARTMENT OF ENERGY \\ under contract DE-AC05-00OR22725
}

Approved For Public Release 


\section{CONTENTS}

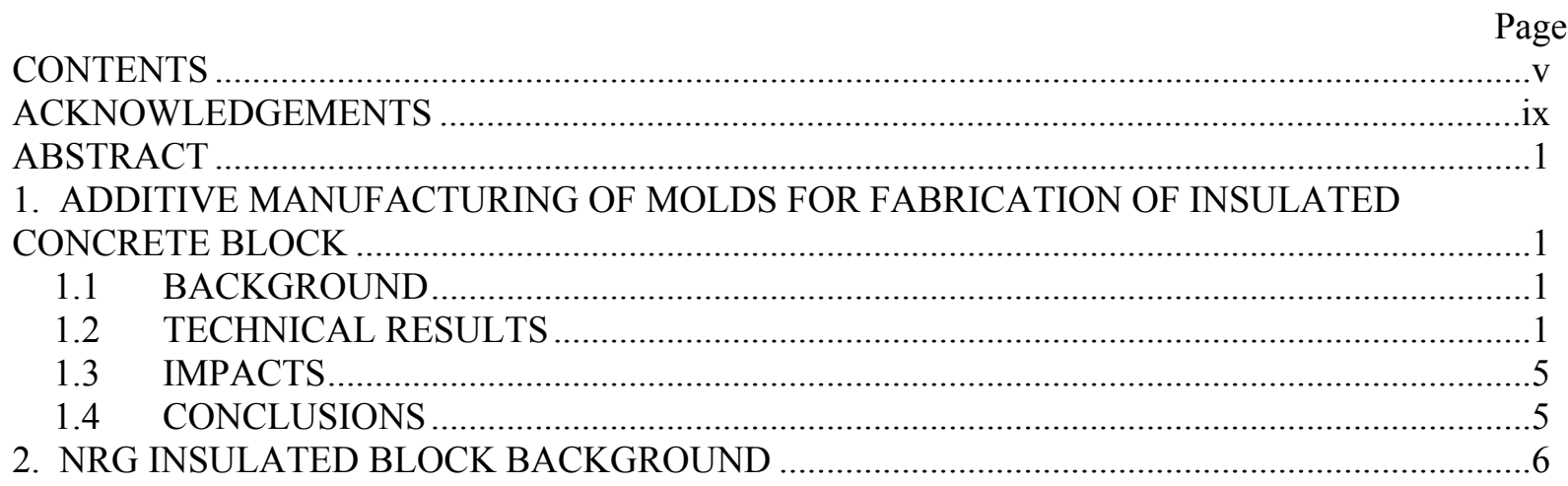




\section{LIST OF FIGURES}

Fig. 1. NRG's insulated concrete masonry unit with rigid EPS insulation. .....................................2

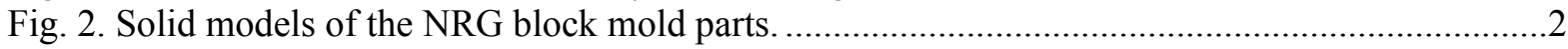

Fig. 3. Mounting the printed mold parts in a block production frame. .................................................

Fig. 4. Printed block molds (right) mounted alongside traditionally manufactured molds (left) in a

block production frame.

Fig. 5. Collapsed block from printed block molds (left) alongside traditionally manufactured block

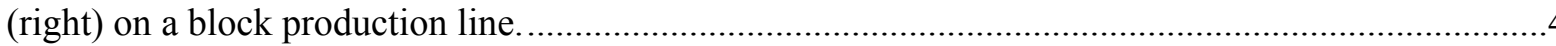




\section{ACKNOWLEDGEMENTS}

This CRADA NFE-16-06317 was conducted as a Technical Collaboration project within the Oak Ridge National Laboratory (ORNL) Manufacturing Demonstration Facility (MDF) sponsored by the US Department of Energy Advanced Manufacturing Office (CPS Agreement Number 24761).

Opportunities for MDF technical collaborations are listed in the announcement "Manufacturing Demonstration Facility Technology Collaborations for US Manufacturers in Advanced

Manufacturing and Materials Technologies" posted at http:/web.ornl.gov/sci/manufacturing/docs/FBO-ORNL-MDF-2013-2.pdf. The goal of technical collaborations is to engage industry partners to participate in short-term, collaborative projects within the Manufacturing Demonstration Facility (MDF) to assess applicability and of new energy efficient manufacturing technologies. Research sponsored by the U.S. Department of Energy, Office of Energy Efficiency and Renewable Energy, Advanced Manufacturing Office, under contract DE-AC0500OR22725 with UT-Battelle, LLC. 



\begin{abstract}
Oak Ridge National Laboratory (ORNL) worked with concrete block manufacturer, NRG Insulated Block, to demonstrate additive manufacturing of a multi-component block mold for its line of insulated blocks. Solid models of the mold parts were constructed from existing two-dimensional drawings, and the parts were fabricated on a Stratasys Fortus 900 using ULTEM ${ }^{\mathrm{TM}}$ 9085. Block mold parts were delivered to NRG and installed on one of their fabrication lines. While form and fit were acceptable, the blocks made from the molds collapsed when extruded from the printed molds during NRG's testing. However, the project demonstrated significant time and cost reductions and achieving proper functionality through the use of different additive manufacturing techniques.
\end{abstract}

\title{
1. ADDITIVE MANUFACTURING OF MOLDS FOR FABRICATION OF INSULATED CONCRETE BLOCK
}

This phase 1 technical collaboration project (MDF-TC-2016-101) began on August 18, 2016. A number of operational delays at one of NRG's production facilities resulted in a long delay between delivery of the test parts from ORNL and their testing in a production environment. Work was completed on December 22, 2017. The collaboration partner, NRG Insulated Block, is a small business. While form and fit of the additively manufactured block molds were acceptable, the molds failed to function properly during NRG's testing; the blocks collapsed when extruded from the printed molds.

\subsection{BACKGROUND}

NRG is a small enterprise with two employees and working with six manufacturing companies who produce the insulated concrete masonry units (CMUs). These concrete blocks (Fig. 1) are uniquely designed to incorporate rigid expanded polystyrene (EPS) thermal insulation, thus eliminating the need for additional insulation that is typically required with traditional concrete block designs. The unique design results in a more complex interior geometry that makes fabrication of the block mold parts time-consuming and expensive. Consequently, NRG approached ORNL seeking a cost-effective way to fabricate these block mold parts using additive manufacturing techniques being developed at the Manufacturing Demonstration Facility (MDF).

\subsection{TECHNICAL RESULTS}

NRG provided a set of two-dimensional drawings that ORNL used to construct solid models of the block mold parts (Fig. 1). The solid models were created and converted into surface models in SolidWorks (Fig. 2). The largest of these parts, the mold core serpentine, is approximately 16.6-in wide by 8.3 -in tall by 4.4 -in deep. Because the parts were relatively small and a smoother surface finish was desirable, ORNL opted to fabricate these parts on its Stratasys Fortus 900 machine rather than on one of the large-scale Big Area Additive Manufacturing (BAAM) machines.

Stratasys's Insight 3D Printing Software was then used to optimize the orientation for each part, to slice the models, and to generate tool paths for fabrication on the Fortus 900 using ULTEM ${ }^{\mathrm{TM}}$ 9085, a high-performance thermoplastic. ULTEM ${ }^{\mathrm{TM}} 9085$ was chosen because it is a resin that is flame-retardant, has a high strength-to-weight ratio, and has a high stiffness. Depending on the 
orientation of the build, ULTEM ${ }^{\mathrm{TM}} 9085$ has a compressive strength yield of $87 \mathrm{MPa}$ to $100 \mathrm{MPa}$, and a compressive modulus of 1,731 $\mathrm{MPa}$ to 7,012 $\mathrm{MPa}$.

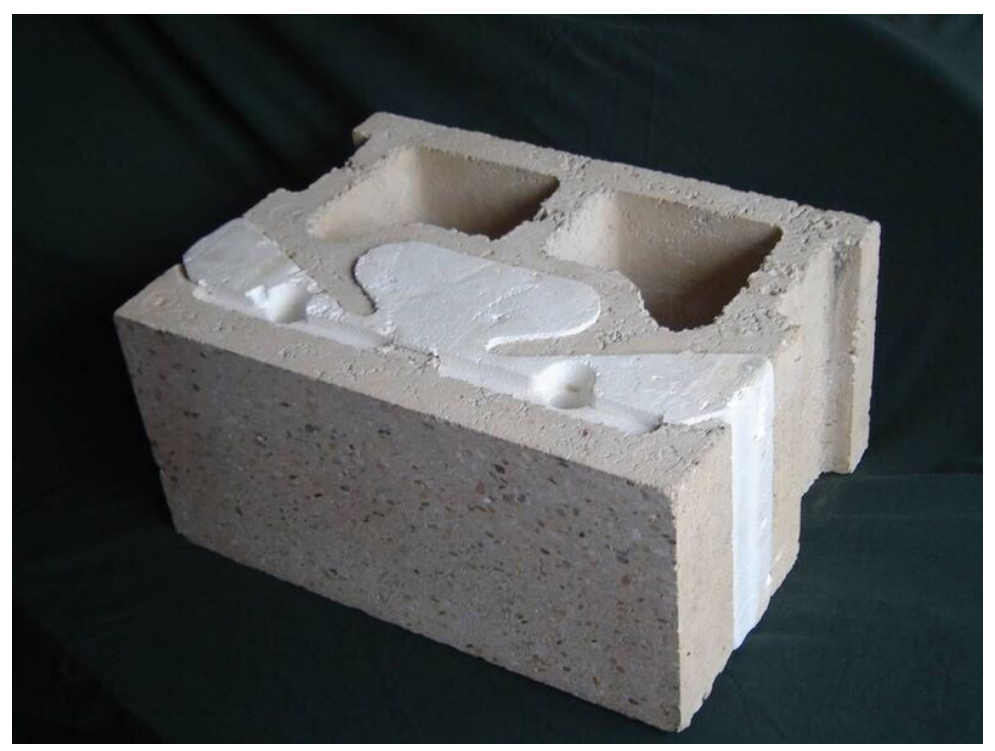

Fig. 1. NRG's insulated concrete masonry unit with rigid EPS insulation.

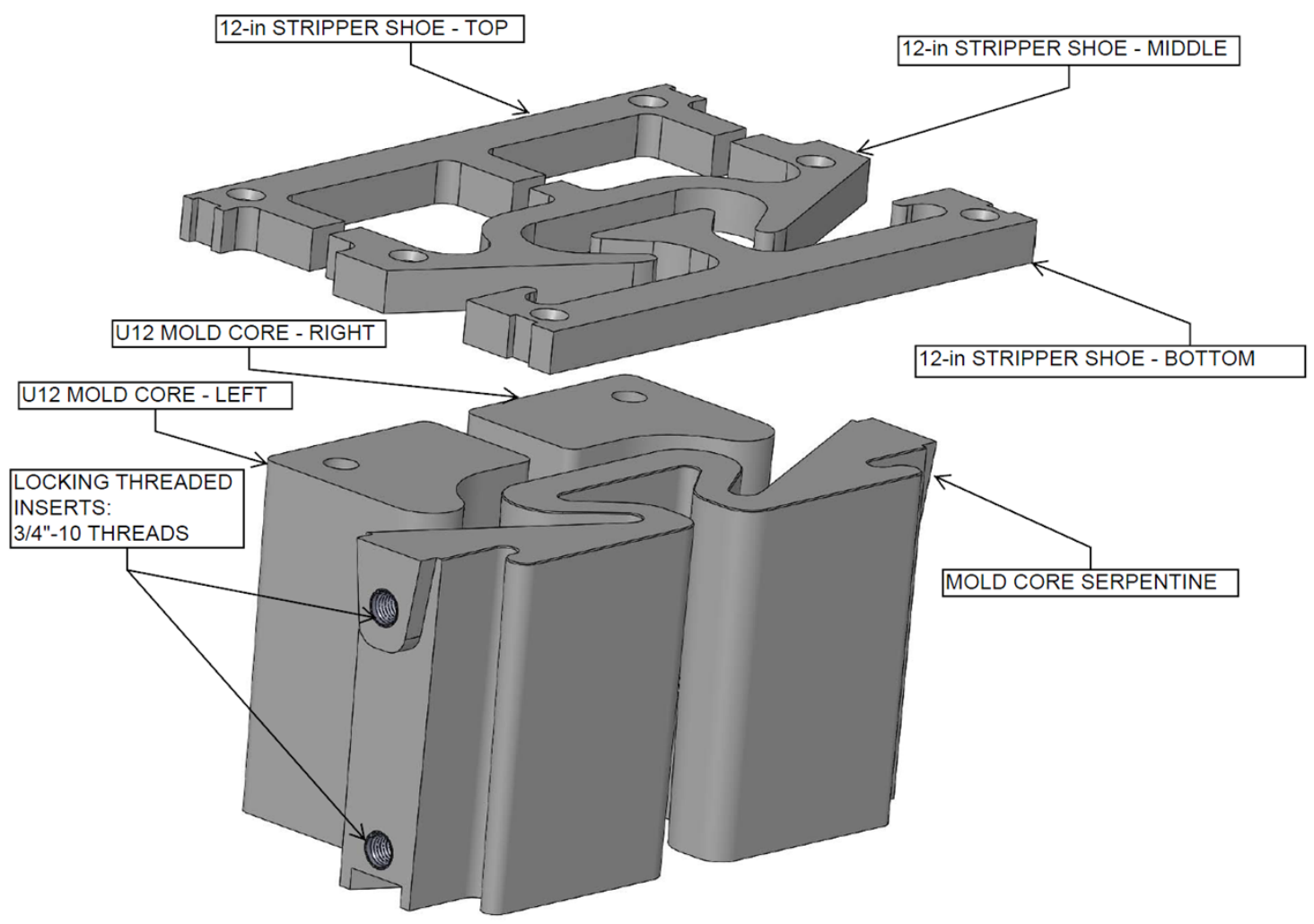

Fig. 2. Solid models of the NRG block mold parts. 
Table 1 shows the volume of model material and support material, as well as print time for each component part. ORNL currently estimates a fully burdened (material plus maintenance and operation of the machine) cost of $\$ 22 / \mathrm{in}^{3}$ for ULTEM ${ }^{\mathrm{TM}}$ parts printed on the Fortus 900 , which makes the fabrication costs of the parts approximately $\$ 13.2 \mathrm{~K}$ per set compared to a conventional manufacturing cost of approximately $\$ 23 \mathrm{~K}$. Additionally, fabrication time for the molds printed on the Fortus was just over eight days, as compared to the 8-10 weeks of lead time required of conventional techniques.

Table 1. Component part material requirements and build times

\begin{tabular}{|l|c|c|c|}
\hline Mold Part & $\begin{array}{c}\text { Model Material } \\
\left(\mathrm{in}^{3}\right)\end{array}$ & $\begin{array}{c}\text { Support Material } \\
\left(\mathrm{in}^{3}\right)\end{array}$ & $\begin{array}{c}\text { Build Time } \\
(\mathrm{hr}: \mathrm{min})\end{array}$ \\
\hline Mold Core Serpentine & 257.37 & 3.06 & $90: 52$ \\
\hline U12 Core - Left & 131.99 & 0.22 & $39: 44$ \\
\hline U12 Core - Right & 131.65 & 0.22 & $39: 40$ \\
\hline 12-in Stripper Shoe - Bottom & 29.14 & 0.34 & $9: 05$ \\
\hline 12-in Stripper Shoe - Middle & 26.31 & 0.31 & $8: 20$ \\
\hline 12-in Stripper Shoe - Top & 23.69 & $0 . .28$ & $7: 31$ \\
\hline Total & 600.15 & 4.15 & $195: 12$ \\
\hline
\end{tabular}

The ORNL printed parts were shipped to NRG Insulated Block in early January 2017. Upon receipt, NRG gave the parts to one of their manufacturers who thought that, except for the core bells, the parts were good enough to try. The concern was that the walls of the U12 core bells were too thin to withstand the stresses generated during block fabrication. ORNL redesigned the bell cores and increased the wall thickness of the tapered bells to 1.25-in. Modified core bells were delivered to NRG in late January 2017 for production testing.

Due to a number of operational delays, NRG was unable to conduct a production test of the printed molds until the last week of November 2017. The block molds were installed on a line in one of NRG's production facilities (Fig. 3). Unfortunately, production of the blocks with the printed molds was unsuccessful. The form and fit of the molds was adequate (Fig. 4), and the molds withstood several production cycles, but the concrete mix collapsed (Fig. 5) when it was extruded from the mold. The failure was due to the relatively rough interior surfaces of the mold and the abrasive nature of the concrete mix that caused the blocks to fail on extrusion.

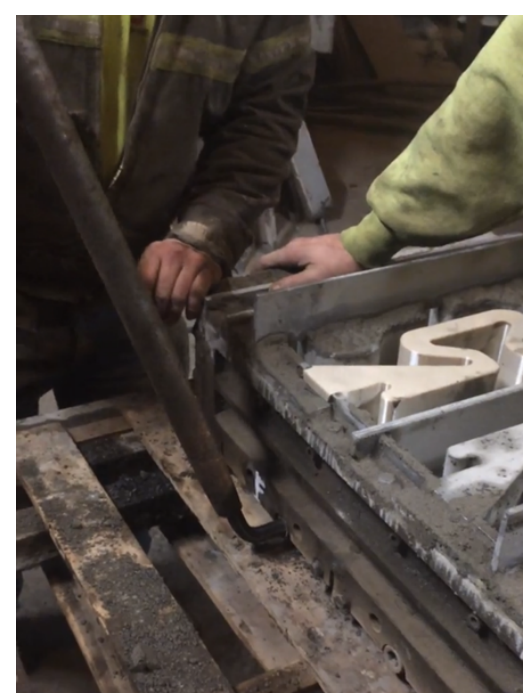

Fig. 3. Mounting the printed mold parts in a block production frame. 


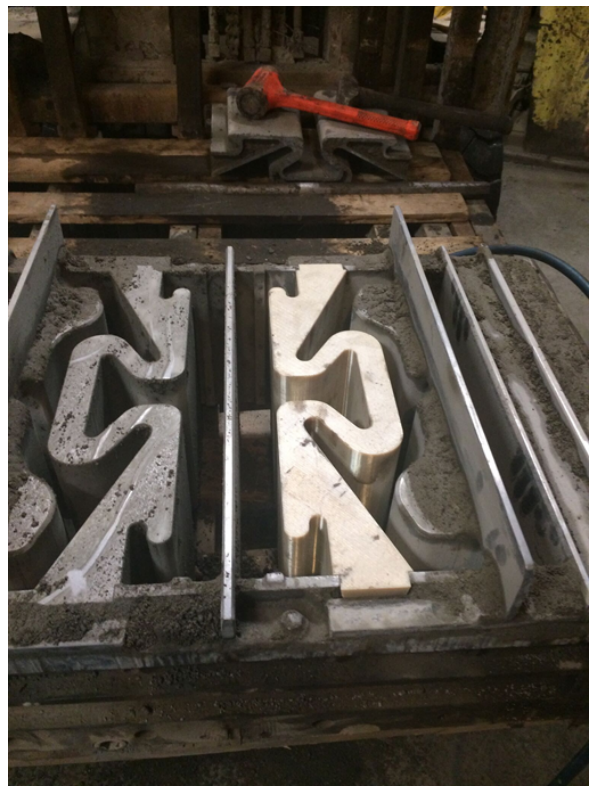

Fig. 4. Printed block molds (right) mounted alongside traditionally manufactured molds (left) in a block production frame.

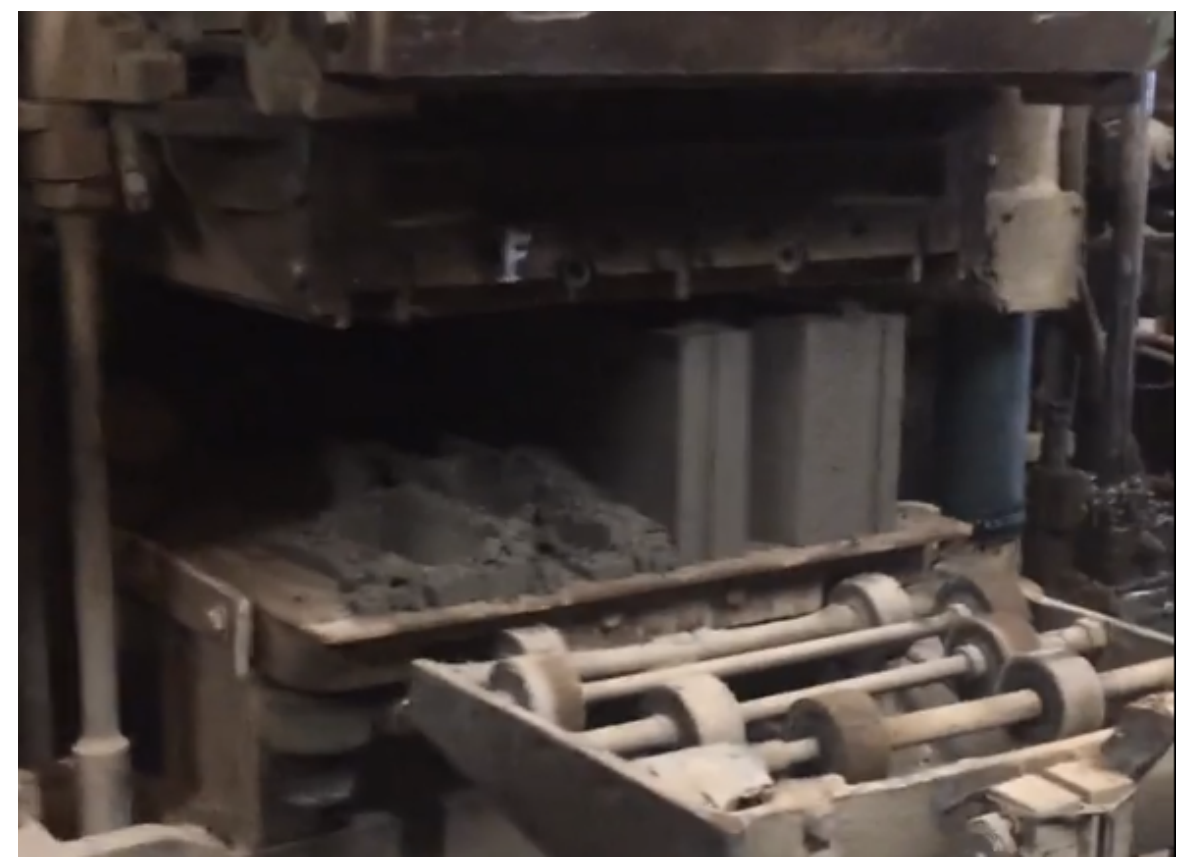

Fig. 5. Collapsed block from printed block molds (left) alongside traditionally manufactured block (right) on a block production line. 


\subsection{IMPACTS}

Despite the failure of the molds created during phase one of this MDF Technical Collaboration, NRG still sees additive manufacturing as a viable approach to reducing its operational costs through the significant time and cost reductions seen through additively manufacturing molds. ORNL currently estimates a fully burdened (material plus maintenance and operation of the machine) cost of $\$ 22 /$ in $^{3}$ for ULTEM ${ }^{\mathrm{TM}}$ parts printed on the Fortus 900 , which makes the fabrication costs of the parts approximately $\$ 13.2 \mathrm{~K}$ per set compared to a conventional manufacturing cost of approximately $\$ 23 \mathrm{~K}$. Additionally, fabrication time for the molds printed on the Fortus 900 was just over eight days, as compared to the 8-10 weeks of lead time required of conventional techniques.

However, the existing business model does not motivate NRG's manufacturing partners to aggressively pursue such alternate paths. NRG has expressed an interest in a phase 2 effort that might take advantage of ORNL's advanced manufacturing experience. Possibilities include fabrication of some of the smaller parts in ORNL's binder-jet machines, such as the ExOne, as well as fabrication of some of the larger parts on one of the metal BAAM machines, such as the Wolf Robotics mBAAM system, currently being researched at ORNL.

\subsection{CONCLUSIONS}

While form and fit of the additively manufactured block molds were acceptable, the molds failed to function properly during NRG's testing; the relatively rough interior surfaces and the abrasive nature of the concrete mix caused the blocks to fail on extrusion. Because of the long delay between delivery of the molds and their actual testing, there was not an opportunity to improve the molds. However, there are possibilities for significant time and cost reductions through using additive manufacturing to fabricate molds. ORNL currently estimates a fully burdened (material plus maintenance and operation of the machine) cost of $\$ 22 /$ in 3 for ULTEM ${ }^{\mathrm{TM}}$ parts printed on the Fortus 900 , which makes the fabrication costs of the parts approximately $\$ 13.2 \mathrm{~K}$ per set compared to a conventional manufacturing cost of approximately $\$ 23 \mathrm{~K}$. Additionally, fabrication time for the molds printed on the Fortus was just over eight days, as compared to the 8-10 weeks of lead time required of conventional techniques.

If the proper process was found and finetuned, there is a possibly of decreasing the cost of mold production approximately $10 \mathrm{~K}$ and the lead time from weeks to days. 


\section{NRG INSULATED BLOCK BACKGROUND}

NRG Insulated Block is a small, two-employee, business that has patent rights to a unique design for insulated concrete masonry units. These blocks, which are manufactured by half a dozen different manufacturers for NRG, incorporate a layer of rigid EPS foam in the core of each block thus eliminating the need for additional insulation to be installed after the exterior walls are constructed. 